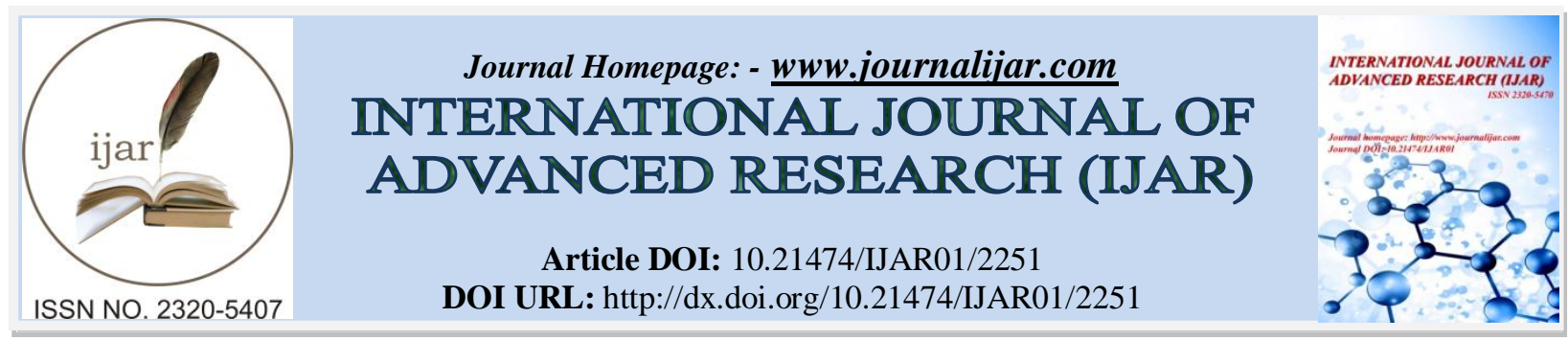

RESEARCH ARTICLE

\title{
CARDIAC INFLAMMATORY MARKERS, LIPID PROFILE AND TOTAL ANTIOXIDANT CAPACITY IN EXPERIMENTAL HYPOTHYROIDISM: A TIME- RESPONSE STUDY IN RATS.
}

\section{"Shereen M. Mahmoud ${ }^{1}$, Faten A. Mohamed ${ }^{2}$ and Hoda I. Bahr'}

1. Department of Forensic Medicine and Toxicology, Faculty of Veterinary Medicine, Suez Canal University.

2. Department of physiology, Faculty of Medicine, Suez Canal University.

3. Department of Biochemistry, Faculty of Veterinary Medicine, Suez Canal University.

\section{Manuscript Info}

\section{Manuscript History}

Received: 29 September 2016

Final Accepted: 30 October 2016

Published: November 2016

Key words:-

PTU, Hypothyrodism, CRP, LDH, cTnI, CPK

\begin{abstract}
Objectives: This study aimed to investigate the effect of induced hypothyrodism on some cardiac inflammatory markers, lipid profile and total antioxidant capacity across two periods of time in rats. Methods: Twenty four adult male albino rats were divided randomly into four groups each of six at which group I served as control for one month; group II received $0.05 \%$ PTU in water orally by gavage for one month, group III served as control for 2 months and group IV received $0.05 \%$ PTU in water orally by gavage for 2 months. Results: hypothyroid state was confirmed by significant decrease of TT3, TT4 and significant increase of TSH in rats treated with $0.05 \%$ PTU for one and two months compared with those of control groups. There was a significant decrease in HDL-C, and TAC with a significant increase in LDL-C, TC, TRIG, CPK, CRP, LDH and cTnI in serum of hypothyroid induced rats compared to control rats for one month, on the other side hypothyroid induced rats for two months expressed a pronounced highly significant decrease in HDL-C and TAC with a highly significant increase in LDL-C, TC, TRIG, CPK, CRP, LDH and cTnI compared to control rats for two months. Our results explain the thyroid activity variation in relation to cardiac markers and indices along time. To conclude, our results showed the occurrence of a state of oxidizing and inflammatory stress with interdependency upon the cardiac muscle in relation to the severity of hypothyroidism and using of some inflammatory markers specifically CRP and LDH which can be such a useful alternative tool in diagnosis of cardiac affections. These data strengthened with the histopathological examination of the heart tissue which proves concurrent inflammation and fibrosis of the cardiomyocytes.
\end{abstract}

Copy Right, IJAR, 2016,. All rights reserved.

\section{Introduction:-}

Thyroid gland is partially responsible for the regulation of the energy output allover the body and this action take place under the control of thyroid hormones which are essential for the development of organs and tissues as well as maintenance of the life quality by regulating cardiac output, lipid catabolism and increase the basal metabolic rate, 
So in case of thyroid dysfunction, it is expected that there will be characteristically insidious, multiple and diverse manifestations allover the body [1].

Thyroid hormones, Triiodothyronine (T3) and thyroxine (T4) critically regulate cardiac performance by many genes encoding important structural proteins in the myocardium [2] which are thyroid hormone responsive [3]. Cardiovascular system responds to minor changes in thyroid hormones levels through alterations of the vascular response and endothelial function [4]. Furthermore, a low thyroid hormone level appears to be an independent predictor of mortality and morbidity in heart diseases [5].

Chronic hypothyroidism in adult rats leads to the loss of coronary arterioles and impaired blood flow; it induces maladaptive changes in the shape of myocytes and the development of heart failure and their severity (depending on the degree and the time elapsed since thyroid hormone deficiency). Experimental studies associated with thyroid dysfunctions and changes in the metabolism and body development are based on the suppression of hormone production [6] and this studies have shown that thyroid disorders not only exert profound effects on cardiac function in rats [7], but also it can be associated with oxidative damage and inflammation which responsible for the progression of heart failure [8] due to oxidative stress [9].

Since hyperlipidemia too can induce oxidative stress, as demonstrated in animals [10, 11], alterations in thyroid hormones will lead to the changes in serum lipid profile causing Dyslipidaemia [12, 13] i.e Characterized by increased total cholesterol (TC), triglycerides (TRIG) and low density lipoprotein cholesterol levels (LDL-C) $[14,15]$ and decreased high density lipoprotein cholesterol levels (HDL-C) [16], as Lipoprotein serum levels increase in hypothyroidism, together with a reduction of oxidative metabolism. An important index of body antioxidant defense is the total antioxidant capacity (TAC) of blood serum, which is studied more and more frequently representing the functional sum of antioxidants present in plasma and it is a measure of the extracellular antioxidant barrier $[17,18]$.

Recent studies suggest that the markers of inflammation may reflect inflammatory process and the pathogenesis of atherosclerosis and have a potential role in the prediction of risk for cardiovascular diseases $[19,20]$ like lactate dehydrogenase (LDH) and creatine phosphokinase (CPK). Among these, CPK has shown promising results as a diagnostic tool for thyroid disease. Serum CPK was first used as a diagnostic aid in progressive muscular dystrophy it has since then become important clinical marker for muscle damage. In recent years, studies have been conducted to establish a relationship of CPK levels in thyroid diseases. Cardiac muscle is affected by hypothyroidism more profoundly in cases of overt hypothyroidism [21, 22]. Thus, the assay of CPK activity in serum may prove to be valuable in screening of thyroid disorders and in the present study, we tried to evaluate the role of CPK as an alternative diagnostic tool in cases of thyroid disorder.

C- reactive protein (CRP) is composed of 187 amino acids and is an acute phase protein synthesized by the stimulation of leukocyte endogenous mediator. Activity of CRP is sensitive, important and well established marker for assessment of inflammation [23].

CRP may increase to over 50,000 times the normal value, starting within $6 \mathrm{~h}$ and reaching a peak in two days and persist for longer periods of time depending on the degree of tissue damage and inflammation. Its concentration depends on the rate of synthesis, since it has a constant half-life in plasma [24]. Studies in the past have created confusion with respect to such inflammatory markers in subclinical hypothyroidism from no risk to definite risk [25]. However, CRP is not a routinely measured parameter in the diagnosis of thyroid diseases, even though due attention should be given to it in the presence of hypothyroidism.

Cardiac troponins are the most specific and sensitive available biochemical cardiac markers [26]. Troponin is a complex of three proteins on the thin filaments of cardiac muscle fibers. During muscle contraction the troponin complex regulates the interaction between the thick and thin filaments. This complex consists of troponin $\mathrm{T}$ (TnT; Tropomyosin binding), troponin I (TnI, Inhibitory component) and troponin $\mathrm{C}$ ( $\mathrm{TnC}$, Calcium binding component). Troponin I is very specific to cardiac muscle and its presence in blood indicates cardiac tissue necrosis. Also, it has been established as sensitive and specific markers of minor myocardial lesions with acute coronary syndrome [27, 28, 29, 30]. Concentrations of cardiac troponin rise 3-4 hours after the cardiac damage and sustained for few days or even more [31]. Presently, the diagnosis of myocardial infarction increasingly is based on increased cardiac troponin concentration [32]. The effect of hypothyroid status on inflammatory markers, as major and 
sensitive risk factors for cardiovascular diseases and developing atherosclerosis in relation to lipid profile and TAC as reference for the oxidative stress was recently studied, but not yet clarified.

PTU drug has been long used to induce hypothyroidism in animal models such as the rat [33], thus the purpose of this study was to evaluate the cardiac dysfunction caused by PTU induced hypothyroidism in adult male albino rats by cardiac inflammatory markers with relation to lipid profile and TAC for two different periods of time.

We anticipated that the consequences of induced low thyroid function in rats for 2 months would have a more pronounced effect than that previously observed for one month in rats treated with PTU and this will be proved by cardiac markers of inflammation.

\section{Materials and Methods:-}

Animals:-

All experiments were performed using 24 adult male albino rats, weighing from 130 to $160 \mathrm{~g}$. They were obtained from the Faculty of veterinary medicine, Zagazig University, Egypt. Food (standard diet, and water were available ad libitum). The animals were acclimated for one week under the same laboratory conditions of photoperiod (12-h light: 12-h dark cycle), a minimum relative humidity of $40 \%$ and room temperature $23 \pm 2^{\circ} \mathrm{C}$. All animal procedures are carried out according to the specifications stated for the proper care and use of laboratory animals [34].

\section{Experimental design:-}

Rats were randomly divided into four groups each of six males, as follow:

- Group I, comprising six individuals and had access to food and water ad libitum and serving as control (1) for one month.

- Group II, whose individuals received 0.05\% PTU (thyrocil $50 \mathrm{mg}$ : AMOUN PHARMACEUTICAL CO.S.A.E., EGYPT) dissolved in water by gavage for one month to induce hypothyroidism, as previously described [35, 36].

- Group III, comprising six individuals and had access to food and water ad libitum and serving as control (2) for two months.

- Group IV, whose rats were treated with $0.05 \%$ PTU orally in water by gavage for two months to induce overt hypothyroidism.

The dose of PTU was selected based on the clinical application and on results from previous experiments in experimental animals against hyperthyroidism treatment [37].

\section{Blood collection:-}

At the end of the experimental period, animals were over night fasted and euthanized with a mixture of ketamine (75 $\mathrm{mg} / \mathrm{kg}$ ) and xylazine $(10 \mathrm{mg} / \mathrm{kg})$ and whole blood samples were collected from the medial canthus of the eye in sterilized plain tubes and left to clot at room temperature for 20 minutes. Sera were separated by centrifugation of the blood at $3000 \mathrm{rpm}$ for 15 minutes and the clear serum was collected and kept frozen at $-20^{\circ} \mathrm{C}$ for determination of various biochemical analyses.

\section{Biochemical assays and analysis:-}

Samples were processed according to the recommendations of the manufacturer of the analytical technique used.

\section{Determination of serum TT3, TT4 and TSH:-}

Establishment of altered thyroid status was confirmed by measurement of serum levels of thyroid hormones TT3, TT4 and TSH. TT3 and TT4 were estimated by ELISA in serum samples using commercial kits from CALBIOTECH, CANADA (Catalogs No. T3043T-100 and T4044T-100 respectively) follow the manufacture instructions using a Coat-A-counter. The concentration of hormones was read from a graph paper. TSH was estimated by ELISA in serum samples using commercial kits from Demeditec Diagnostics TSH rat ELISA, Germany, following the manufacture instructions.

Serum Oxidative Stress Measurements; Total Antioxidant Capacity (TAC):-

TAC in serum was measured by using a Randox assay (CELL BIOLAB, INC. USA). The assay was performed in accordance with the manufacturer instructions $[38,39]$. 
Serum Total cholesterol, Triglycerides, HDL-C and LDL-C:-

Concentrations of TC, TRIG and HDL-C were measured by means of B.M. Hitachi 742 auto-analyzer, using VITRO SCIENT diagnostic kits, Germany and enzymatic methods following the manufacture instructions. Concentration of LDL-C was calculated according to the Friedewald formula (1972) [40].

\section{Estimation of serum LDH and CPK activities:-}

Serum CPK and LDH were measured using commercial kits from Abnova (Catalog Number KA1665) (UK) and VITRO SCIENT diagnostic kits (Germany) as indices of cardiac integrity. The activity of serum enzymes were expressed as IU/L.

\section{Estimation of serum CRP and Cardiac TROPONIN I activities:-}

$\mathrm{C}$ - reactive protein levels were measured using Rat- CRP ELISA kit (BD ${ }^{\mathrm{TM}}$ ELISA, USA) following manufacture instructions. Cardiac troponin I (cTnI, CALBIOTECH, Troponin I ELISA, CANADA) was measured in the serum according to the manufacture procedures using a spectrophotometric reader Power Wave XT (BioTek, USA).

\section{Histopathology:-}

The $10 \%$ neutral formalin-fixed heart tissues were embedded in paraffin, and 4- $\mu \mathrm{m}$ thick sections were cut. Paraffinembedded sections of the hearts were stained with either hematoxylin-eosin or Masson's trichrome (SigmaAldrich, St. Louis, Missouri, USA) for histopathological evaluation according to (Bancroff et al., 1990) [41]. After staining, the sections were dehydrated in ethanol/water baths with decreasing water content and finally rinsed in xylene before being mounted with a permanent mounting medium. Gross examination and histological sections were analyzed by two independent pathologists in a blinded fashion.

\section{Statistical analysis:-}

Data of the present study were statistically analyzed using One-way Analysis of Variance (ANOVA), followed by means separation for multiple means comparison using Duncan's multiple range test (DMRT). The correlations were assessed by Pearson correlation. Statistical analyses were applied by Spss for windows version, 20. Results were considered significant at probability level $\leq 0.05$.

\section{RESULTS:-}

Effects of thyroid dysfunction on serum TT3, TT4, TSH and TAC:-

Variations in TT3, TT4, TSH and TAC concentrations are illustrated in Table (1) and Figure (1). TT3 and TT4 underwent a highly significant decrease $(\mathrm{P} \leq 0.01)$ in the hypothyroid rats $\left(0.07^{\mathrm{b}} \pm 0.01\right.$ and $\left.26.2^{\mathrm{b}} \pm 0.89 \mathrm{ng} / \mathrm{dl}\right)$ and $\left(0.04^{\mathrm{b}} \pm 0.01\right.$ and $\left.15^{\mathrm{c}} \pm 1.35 \mathrm{ng} / \mathrm{dl}\right)$ as compared to the healthy controls $\left(0.42^{\mathrm{a}} \pm 0.04\right.$ and $\left.45.9^{\mathrm{a}} \pm 0.58 \mathrm{ng} / \mathrm{dl}\right)$ and $\left(0.31^{\mathrm{a}} \pm 0.02\right.$ and $\left.45.8^{\mathrm{a}} \pm 1.3 \mathrm{ng} / \mathrm{dl}\right)$ after one and two months of PTU oral administration respectively confirming the establishment of hypothyroidism.

There were also a highly significant increase $(\mathrm{P} \leq 0.01)$ of TSH levels in the hypothyroid rats $\quad\left(10.9^{\mathrm{c}} \pm 0.66\right.$ $\mu \mathrm{IU} / \mathrm{ml})$ and $\left(15.4^{\mathrm{a}} \pm 0.78 \mu \mathrm{IU} / \mathrm{ml}\right)$ as compared to the healthy individuals $\left(2.78^{\mathrm{c}} \pm 0.21 \mu \mathrm{IU} / \mathrm{ml}\right)$ and $\left(2.88^{\mathrm{c}} \pm 0.22\right.$ $\mu \mathrm{IU} / \mathrm{ml}$ ) after one and two months of PTU oral administration respectively which also confirmed the hypothyroid state.

Serum TAC, was highly significantly $(\mathrm{P} \leq 0.01)$ lower in hypothyroid-treated rats $\left(10.9^{\mathrm{b}} \pm 0.16 \mathrm{mM}\right)$ and $\left(8.36^{\mathrm{c}} \pm\right.$ $0.33 \mathrm{mM})$ compared with those of controls $\left(16.1^{\mathrm{a}} \pm 0.68 \mathrm{mM}\right)$ and $\left(15.3^{\mathrm{a}} \pm 0.67 \mathrm{mM}\right)$ after one and two months of PTU oral administration respectively.

Table 1:- Effects of thyroid dysfunction on serum TT3, TT4, TSH and TAC for one and two months of $0.05 \%$ PTU oral administration.

\begin{tabular}{|c|c|c|c|c|}
\hline Time & \multicolumn{2}{|c|}{ One Month } & \multicolumn{2}{c|}{ Two Months } \\
\hline Parameter & Control I & Hypo. I & Control II & Hypo. II \\
& & & & $0.04^{\mathrm{b}} \pm 0.01$ \\
\hline TT3 $(\mathbf{n g} / \mathbf{d l})$ & $0.42^{\mathrm{a}} \pm 0.04$ & $0.07^{\mathrm{b}} \pm 0.01$ & $0.31^{\mathrm{a}} \pm 0.02$ & $15^{\mathrm{c}} \pm 1.35$ \\
\hline TT4 $(\mathbf{n g} / \mathbf{d l})$ & $45.9^{\mathrm{a}} \pm 0.58$ & $26.2^{\mathrm{b}} \pm 0.89$ & $45.8^{\mathrm{a}} \pm 1.3$ & $15.4^{\mathrm{a}} \pm 0.78$ \\
\hline TSH $(\boldsymbol{\mu} \mathbf{I U} / \mathbf{m l})$ & $2.78^{\mathrm{c}} \pm 0.21$ & $10.9^{\mathrm{c}} \pm 0.66$ & $2.88^{\mathrm{c}} \pm 0.22$ & $8.36^{\mathrm{c}} \pm 0.33$ \\
\hline TAC $(\mathbf{m M})$ & $16.1^{\mathrm{a}} \pm 0.68$ & $10.9^{\mathrm{b}} \pm 0.16$ & $15.3^{\mathrm{a}} \pm 0.67$ & \\
\hline
\end{tabular}


TT3: total triiodothyronine; TT4: total thyroxine; TSH: thyroid stimulating hormone; TAC: total antioxidant capacity. Values are expressed as Mean \pm SE, values in each row with different superscripts (a, b, c) are significantly different at $\mathrm{P} \leq 0.05$ and highly significant different at $\mathrm{P} \leq 0.01$. $\mathrm{n}=6$ rats/group.

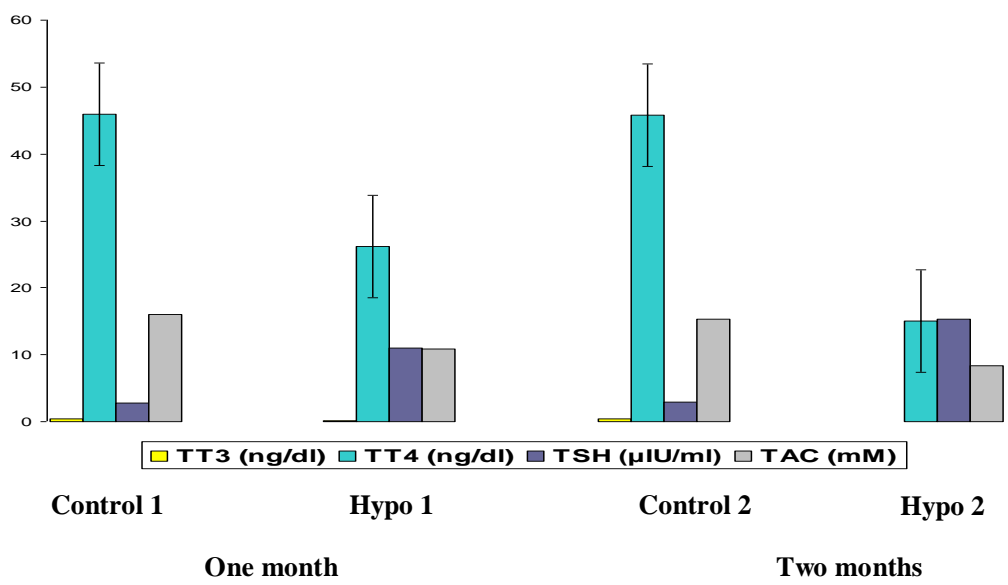

Figure 1:- Effects of thyroid dysfunction on serum TT3, TT4, TSH and TAC for one and two months of $0.05 \%$ PTU induced hypothyrodism.

\section{Effects of thyroid dysfunction on serum TC, TRIG, HDL and LDL:-}

Table (2) and Figure (2) showed a highly significant $(\mathrm{P} \leq 0.01)$ increased levels of TC in the hypothyroid rats $\left(139.9^{\mathrm{b}} \pm 2.57 \mathrm{mg} / \mathrm{dl}\right)$ and $\left(162.2^{\mathrm{a}} \pm 2.23 \mathrm{mg} / \mathrm{dl}\right)$ as compared to the healthy controls $\left(108.1^{\mathrm{d}} \pm 3.27 \mathrm{mg} / \mathrm{dl}\right)$ and $\left(124.9^{\mathrm{c}} \pm 6.17 \mathrm{mg} / \mathrm{dl}\right)$ after one and two months of PTU oral administration respectively.

There were also a highly significant $(\mathrm{P} \leq 0.01)$ increase levels of TRIG in the hypothyroid rats $\left(1018^{\mathrm{c}} \pm 16.7\right.$ $\mathrm{mg} / \mathrm{dl})$ and $\left(1305^{\mathrm{a}} \pm 11.2 \mathrm{mg} / \mathrm{dl}\right)$ as compared to the healthy individuals $\left(659.1^{\mathrm{d}} \pm 25.9 \mathrm{mg} / \mathrm{dl}\right)$ and $\left(834.9^{\mathrm{c}} \pm 56.2\right.$ $\mathrm{mg} / \mathrm{dl}$ ) after one and two months of PTU oral administration respectively.

There were also a highly significant $(\mathrm{P} \leq 0.01)$ decrease levels of HDL-C in the hypothyroid patients $\left(27.16^{\mathrm{b}} \pm 0.91\right.$ $\mathrm{mg} / \mathrm{dl})$ and $\left(13.28^{\mathrm{c}} \pm 0.99 \mathrm{mg} / \mathrm{dl}\right)$ as compared to the healthy individuals $\left(32.24^{\mathrm{a}} \pm 0.61 \mathrm{mg} / \mathrm{dl}\right)$ and $\left(31.65^{\mathrm{a}} \pm 0.77\right.$ $\mathrm{mg} / \mathrm{dl}$ ) after one and two months of PTU oral administration respectively.

There were also a highly significant $(\mathrm{P} \leq 0.01)$ increase levels of LDL-C in the hypothyroid rats $\quad\left(90.88^{\mathrm{b}} \pm 1.28\right.$ $\mathrm{mg} / \mathrm{dl})$ and $\left(112.1^{\mathrm{a}} \pm 0.86 \mathrm{mg} / \mathrm{dl}\right)$ as compared to the healthy individuals $\left(55.60^{\mathrm{d}} \pm 2.37 \mathrm{mg} / \mathrm{dl}\right)$ and $\left(73.38^{\mathrm{c}} \pm 5.7\right.$ $\mathrm{mg} / \mathrm{dl}$ ) after one and two months of PTU oral administration respectively.

Table 2:- Effects of thyroid dysfunction on serum TC, TRIG, HDL and LDL for one and two months of $0.05 \%$ PTU oral administration.

\begin{tabular}{|c|c|c|c|c|}
\hline Time & \multicolumn{2}{|c|}{ One Month } & \multicolumn{2}{c|}{ Two Months } \\
\hline Parameter & Control I & Hypo. I & Control II & Hypo. II \\
\hline TC $(\mathbf{m g} / \mathbf{d l})$ & $108.1^{\mathrm{d}} \pm 3.27$ & $139.9^{\mathrm{b}} \pm 2.57$ & $124.9^{\mathrm{c}} \pm 6.17$ & $162.2^{\mathrm{a}} \pm 2.23$ \\
\hline TRIG (mg/dl) & $659.1^{\mathrm{d}} \pm 25.9$ & $1018^{\mathrm{c}} \pm 16.7$ & $834.9^{\mathrm{c}} \pm 56.2$ & $1305^{\mathrm{a}} \pm 11.2$ \\
\hline HDL $(\mathbf{m g} / \mathbf{d l})$ & $32.24^{\mathrm{a}} \pm 0.61$ & $27.16^{\mathrm{b}} \pm 0.91$ & $31.65^{\mathrm{a}} \pm 0.77$ & $13.28^{\mathrm{c}} \pm 0.99$ \\
\hline LDL $(\mathbf{m g} / \mathbf{d l})$ & $55.60^{\mathrm{d}} \pm 2.37$ & $90.88^{\mathrm{b}} \pm 1.28$ & $73.38^{\mathrm{c}} \pm 5.7$ & $112.1^{\mathrm{a}} \pm 0.86$ \\
\hline
\end{tabular}

TC: total cholesterol; TRIG: triglycerides; HDL-C: high density lipoprotein; LDL-C: low density lipoprotein. Values are expressed as Mean \pm SE, values in each row with different superscripts (a, b, c, d) are significantly different at $P \leq 0.05$ and highly significant different at $P \leq 0.01$. $n=6$ rats/group. 


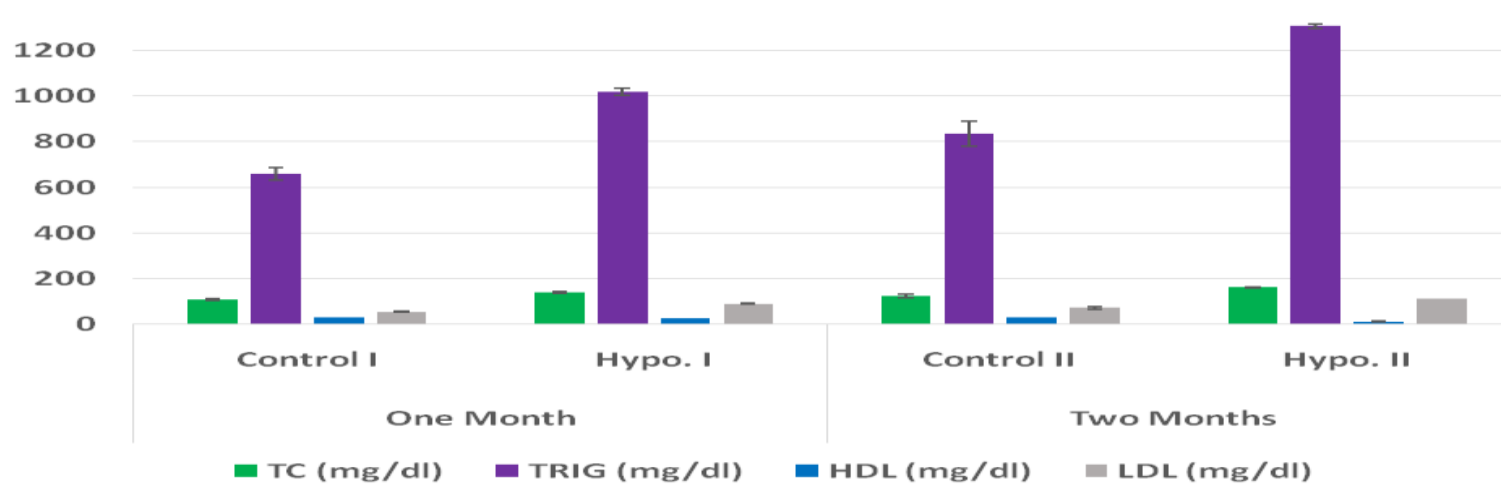

Figure 2:- Effects of thyroid dysfunction on serum TC, TRIG, HDL and LDL for one and two months of $0.05 \%$ PTU oral administration.

\section{Serum LDH, CPK, CRP and cTnI:-}

Table (3) and Figures $(3,4)$ showed some biochemical parameters that indicated heart injury in rats. LDH activities were highly significant increased $(\mathrm{P} \leq 0.01)$ in hypothyroid rats $\left(720.4^{\mathrm{a}} \pm 70.79 \mathrm{U} / \mathrm{L}\right)$ and $\left(672.5^{\mathrm{a}} \pm 59.55\right.$ $\mathrm{U} / \mathrm{L})$ compared to those of controls $\left(104.4^{\mathrm{b}} \pm 3.51 \mathrm{U} / \mathrm{L}\right)$ and $\left(195.2^{\mathrm{b}} \pm 4.37 \mathrm{U} / \mathrm{L}\right)$ after one and two months of PTU oral administration respectively, while serum CPK activities shows highly significant increase hypothyroid rats $\left(186^{\mathrm{a}} \pm 4.19 \mathrm{U} / \mathrm{L}\right)$ and $\left(163^{\mathrm{b}} \pm 1.69 \mathrm{U} / \mathrm{L}\right)$ compared with controls rats $(\mathrm{P} \leq 0.01)$ in $\mathrm{U} / \mathrm{L})$ and $\left(116.4^{\mathrm{d}} \pm 3.66 \mathrm{U} / \mathrm{L}\right)$ after one and two months of PTU oral administration respectively.

$\left(141.4^{\mathrm{c}} \pm 4.82\right.$

The CRP levels showed also highly significant $(\mathrm{P} \leq 0.01)$ increase in the hypothyroid rats $\mathrm{mg} / \mathrm{L})$ and $\left(5.63^{\mathrm{a}} \pm 0.11 \mathrm{mg} / \mathrm{L}\right)$ as compared to the healthy individuals $\left(4.46^{\mathrm{c}} \pm 0.01 \mathrm{mg} / \mathrm{L}\right)$ and $\mathrm{mg} / \mathrm{L}$ ) after one and two months of PTU oral administration respectively.

Meanwhile, cTnI levels were also highly significant $(\mathrm{P} \leq 0.01)$ increased in the hypothyroid rats $\left(0.13^{\mathrm{a}} \pm 0.01\right.$ $\mathrm{mg} / \mathrm{L})$ and $\left(0.14^{\mathrm{a}} \pm 0.18 \mathrm{mg} / \mathrm{L}\right)$ compared to control rats $\left(0.08^{\mathrm{b}} \pm 0.01 \mathrm{mg} / \mathrm{L}\right)$ and $\left(0.05^{\mathrm{d}} \pm 0.01 \mathrm{mg} / \mathrm{L}\right)$ in one and two months of PTU oral administration respectively.

Table 3:- Effects of thyroid dysfunction on serum LDH, CPK, CRP and cTnI for one and two months of $0.05 \%$ PTU oral administration.

\begin{tabular}{|c|c|c|c|c|}
\hline Time & \multicolumn{2}{|c|}{ One Month } & \multicolumn{2}{c|}{ Two Months } \\
\hline Parameter & Control I & Hypo. I & Control II & Hypo. II \\
\hline LDH (U/L) & $104.4^{\mathrm{b}} \pm 3.51$ & $720.4^{\mathrm{a}} \pm 70.79$ & $195.2^{\mathrm{b}} \pm 4.37$ & $672.5^{\mathrm{a}} \pm 59.55$ \\
\hline CPK (U/L) & $116.4^{\mathrm{d}} \pm 3.66$ & $163^{\mathrm{b}} \pm 1.69$ & $141.4^{\mathrm{c}} \pm 4.82$ & $186^{\mathrm{a}} \pm 4.19$ \\
\hline CRP (mg/L) & $4.46^{\mathrm{c}} \pm 0.01$ & $5.15^{\mathrm{b}} \pm 0.22$ & $4.55^{\mathrm{c}} \pm 0.13$ & $5.63^{\mathrm{a}} \pm 0.11$ \\
\hline cTnI (mg/L) & $0.08^{\mathrm{c}} \pm 0.01$ & $0.13^{\mathrm{b}} \pm 0.01$ & $0.05^{\mathrm{d}} \pm 0.01$ & $0.14^{\mathrm{a}} \pm 0.18$ \\
\hline
\end{tabular}

LDH: lactate dehydrogenase; CPK: creatine phosphokinase; CRP: c- reactive protein; cTnI: cardiac troponine I. Values are expressed as Mean \pm SE, values in each row with different superscripts (a, b, c, d) are significantly different at $\mathrm{P} \leq 0.05$ and highly significant different at $\mathrm{P} \leq 0.01$. $\mathrm{n}=6$ rats/group. 


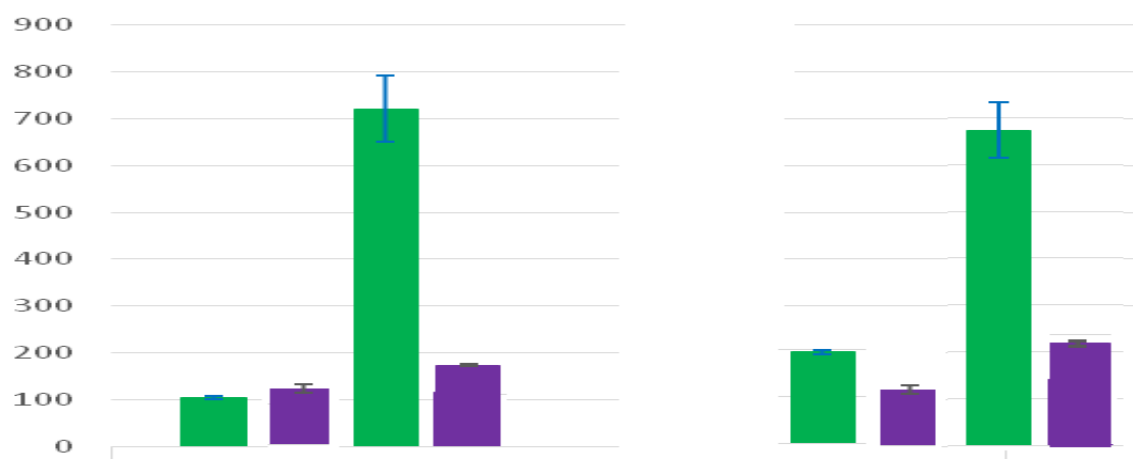

Control $1 \quad$ Hypo 1 $\square \operatorname{CPK}(\mathrm{U} / \mathrm{L})$

Control 2 Hypo 2

Figure 3:- Effects of hypothyro and CPK for one

ral administration.

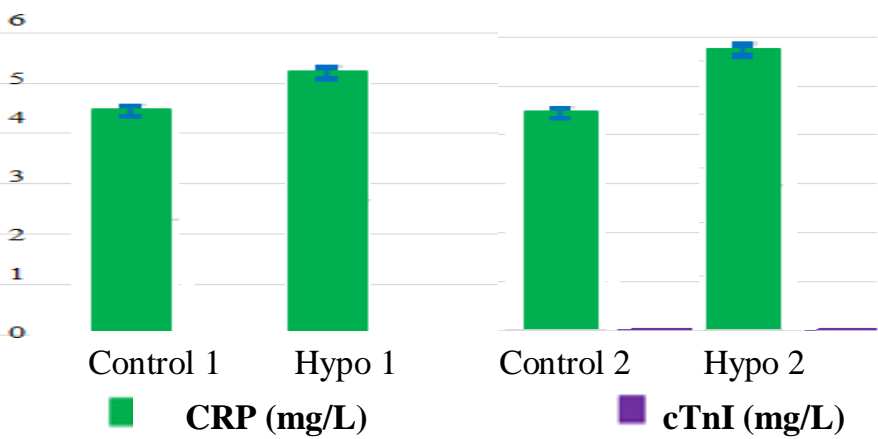

Figure 4:- Effects of thyroid dysfunction on serum CRP and cTnI for one and two months of $0.05 \%$ PTU oral administration.

The correlation results:-

The correlations between cardiac markers and all variables are illustrated in Table (4) that showed highly significant correlation between LDH and CRP with all parameters.

Table 4:- Pearson correlation analyses of cardiac markers with TT3, TT4, TSH, TAC and lipid profile

\begin{tabular}{|c|c|c|c|c|}
\hline parameters & LDH & CPK & CRP & cTnI \\
\hline TT3 & $-.896^{* * *}$ & -.091 & $-.761^{* * *}$ & -.337 \\
\hline TT4 & $-.828^{* * *}$ & -.097 & $-.758^{* * *}$ & -.270 \\
\hline TSH & $.868^{* * *}$ & .120 & $.835^{* *}$ & $.402^{* *}$ \\
\hline TAC & $-.835^{* * *}$ & $-.163^{* *}$ & -.775 & $-.355^{* * *}$ \\
\hline HDL & $-.664^{* * *}$ & $-.199^{* *}$ & $-.797^{* * *}$ & $-.318^{* * *}$ \\
\hline LDL & $.789^{* * *}$ & $.373^{* * *}$ & $.760^{* *}$ & $.440^{* * *}$ \\
\hline TC & .750 & $.360^{* *}$ & $.740^{* *}$ & $.430^{* *}$ \\
\hline TRIG & $.776^{* * *}$ & .352 & $.781^{* *}$ & $.431^{* *}$ \\
\hline
\end{tabular}

** Correlation is significant at the 0.01 level (2-tailed).

* Correlation is significant at the 0.05 level (2-tailed).

Tables $(5,6)$ showed strong negative and positive correlations of all lipid profile parameters with TSH and thyroid hormones respectively except HDL that showed the opposite correlation. TAC had strong negative and positive correlation with TSH and thyroid hormones respectively.

Table 5:- Pearson correlation analyses of Lipid profile with TT3, TT4 and TSH

\begin{tabular}{|c|c|c|c|c|}
\hline parameters & HDL & LDL & TC & TRIG \\
\hline TT3 & $.741^{* * * *}$ & $-.865^{* *}$ & $-.837^{* * *}$ & $.933^{* * *}$ \\
\hline TT4 & $.879^{* * * *}$ & $-.873^{* * *}$ & $-.845^{* * *}$ & $-.888^{* * *}$ \\
\hline TSH & $-.884^{* * *}$ & $.872^{* * *}$ & $.852^{* *}$ & $.892^{* *}$ \\
\hline
\end{tabular}

** Correlation is significant at the 0.01 level (2-tailed).

* Correlation is significant at the 0.05 level (2-tailed). 
Table 6:- Pearson correlation analyses of TAC with TT3, TT4 and TSH

\begin{tabular}{|c|c|}
\hline parameters & TAC \\
\hline TT3 & $.933^{* *}$ \\
\hline TT4 & $.941^{* *}$ \\
\hline TSH & $-.932^{* *}$ \\
\hline
\end{tabular}

** Correlation is significant at the 0.01 level (2-tailed).

* Correlation is significant at the 0.05 level (2-tailed).

\section{Histopathological results:-}
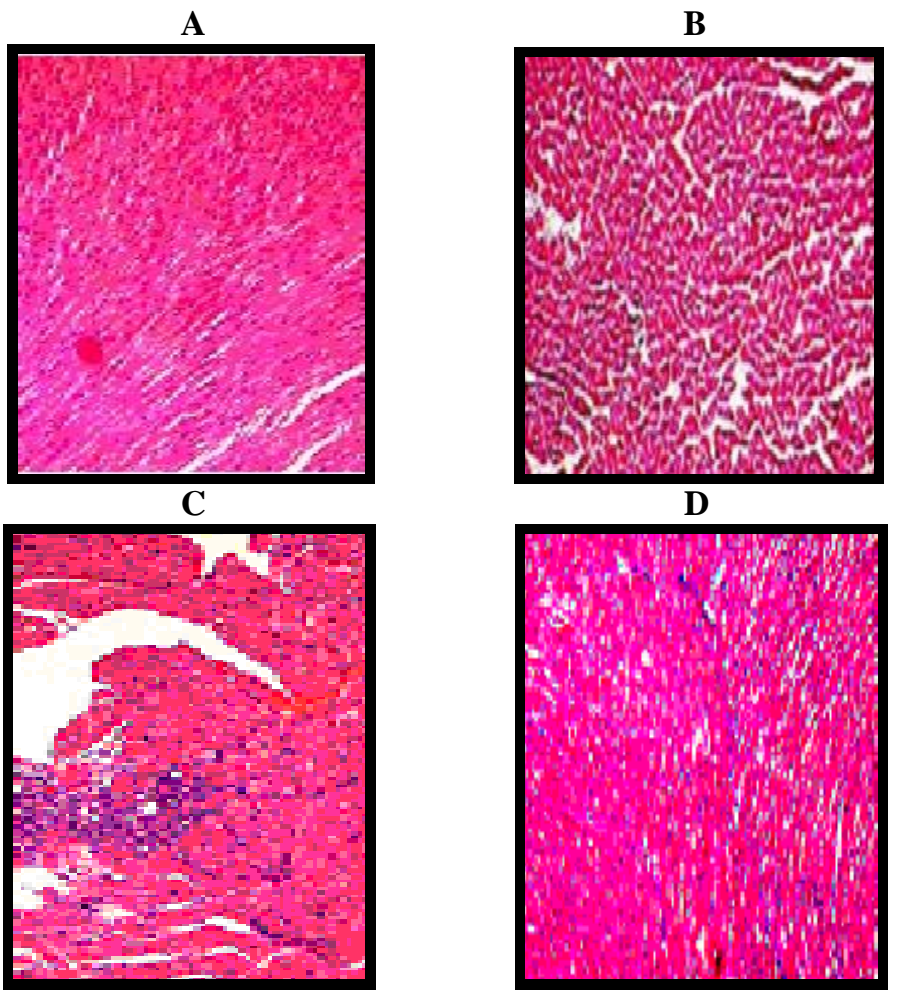

$\mathbf{E}$
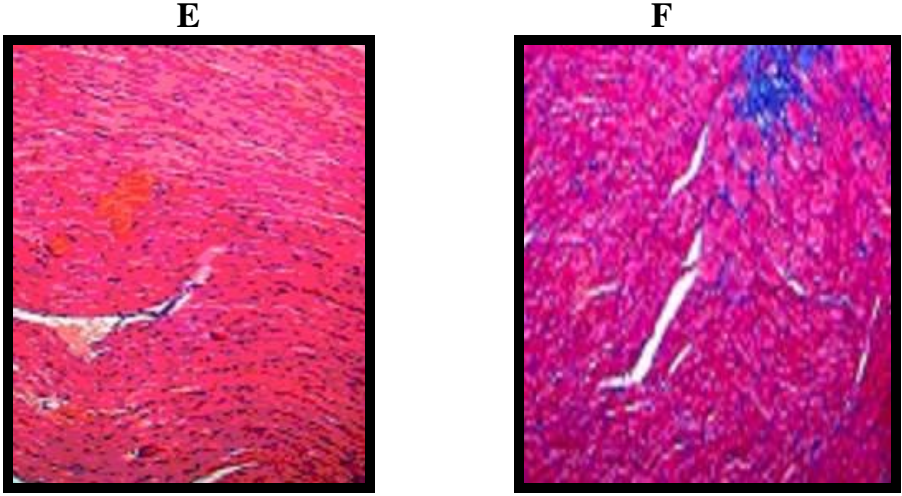

Figure 5:- A and B: Heart of the control group stained with hematoxylin-eosin (x40) (A) and Masson's trichrome (B) showing a well-organized lamellar arrangement of cardiomyocytes without signs of fibrosis. C and D: heart of the $0.05 \%$ PTU group after one month of induction stained with hematoxylin-eosin (x40) (C) and Masson's trichrome (D) showing infiltration of leucocytes (blue color). $\mathbf{E}$ and $\mathbf{F}$ : heart of the $0.05 \%$ PTU group after two month of induction stained with hematoxylin-eosin (x40) (E) and Masson's trichrome (F) showing cardiomyocytes hypertrophy with increased size of the nuclei and presenting area of fibrosis. 


\section{Discussion:-}

After one and two months of oral 0.05\% PTU treatment in rats, the serum TT3 and TT4 levels were depressed, whereas the serum TSH level drastically increased, indicating the establishment of hypothyroidism. This apparent discrepancy in the levels of thyroid hormones and TSH has been described in previous literature [42].

The improper thyroid function is associated not only with general metabolic disturbance but also with a number of other apparently unrelated health issues such as cardiac diseases [43, 44] as Triiodothyronine (T3) exerts effects on various sodium, potassium, and calcium channels in the heart, and thus changes in intracellular levels of calcium and potassium can increase inotropy and chronotropy [45].

Recent studies demonstrated that hamsters with dilated cardiomyopathy have subclinical hypothyroidism and benefited significantly from thyroid hormone treatment, another study demonstrated greater infarct size in dogs with PTU induced hypothyroidism. Our study showed that hypothyroidism in rats is related to the development of cardiac inflammation along with function decline (with oxidative stress that was observed by depression of TAC and disturbance of lipid profile). However, hypothyroid state may increase the risk of the morbidity associated with circulatory diseases and ischemic heart disease. TAC shows overall amount of antioxidants in the body. The advantage of this test is that it measures all antioxidant, not just in a bioactive component $[46,47]$.

Thyroid hormones influence all major metabolic pathways. Their most obvious and well-known action is an increase in basal energy expenditure through actions on protein, carbohydrate, and lipid metabolism. With specific regard to liver lipid metabolism, thyroid hormones stimulate fatty acid and cholesterol synthesis by inducing 3-hydroxy-3methyl- 9 glutaryl co A reductase in liver and also affect lipoprotein lipase activity thus, influence the hydrolysis of triglycerides into VLDL and chylomicrons into fatty acids and glycerol, increase mobilization of plasma cholesterol and triglycerides, and stimulate fatty acid and cholesterol degradation [48].

Experimental hypothyroidism induced by PTU treatment is characterized by altered lipid profile as a well-known manifestation of thyroid dysfunction [49]. In hypothyroidism, increased total cholesterol is due to the decreased catabolism and increased levels of serum cholesterol. The catabolism of cholesterol into bile is mediated by the enzyme cholesterol $7 \alpha$-hydroxylase. This liver-specific enzyme is negatively regulated by $\mathrm{T} 3$ and may contribute to hypercholesterolemia [50]. Hypertriglyceridemia is due to decreased activity of lipoprotein lipase in the adipose tissue Moreover, because thyroid hormone has direct effects on fatty acid synthesis and desaturation, membrane phospholipids fatty acid composition is significantly altered in the hypothyroid state [51].

Thyroid hormones also affect cholesterol ester transfer protein (CETP) and hepatic lipase activity which is decreased in hypothyroidism this will cause changes in total high density lipoprotein (HDL) levels. Thyroid hormones especially Triiodothyronine (T3) induces LDL receptor gene expression in the liver and enhances LDL clearance, but in hypothyroidism there is a down regulation of LDL receptor gene and decreased number of LDL receptors in liver this causes delayed clearance of LDL from circulation [52] followed by increased levels of LDL and this leads to Hypercholesterolemia [48].

Our study supports the hypothesis that hypothyroidism is associated with relatively increased inflammatory markers levels along with dyslipidaemia compared to control group and they can give rise to future development of cardiovascular risk. To explore such effects of hypothyroidism on cardiac function, we had investigated circulating enzymes activities that are markers of cardiac function. The enzymatic activities profile in hypothyroidism was greatly increased. Such increases corresponded with several cardiac pathologies such as infarcts. In effect, many studies had reported that LDH and CPK elevated activities are consistently correlated with cardiac dysfunction [53].

Recently CRP has emerged as new cardiovascular risk factors in which inflammation plays a significant contributory role. Cardiovascular disease is seen more frequently in hypothyroidism, but studies on changes of this marker with respect to thyroid function status have produced variable results. The association of hypothyroidism with plasma pro-inflammatory markers such as CRP has been demonstrated in some studies [54]. In this study, the degree of elevation of CRP in serum was correlated with the severity of hypothyroidism, other Studies have described an elevated concentration of CRP [55] which was positively correlated with TSH concentration, Wonn et al., (2004) [56] proposed that CRP directly stimulates the inflammatory reaction by inducing the expression of adhesion molecule in vascular endothelial cells. Lack of thyroid hormones leads to slowing down the overall metabolic rate, and all the biochemical processes may be impaired under those circumstances. Thus, the rate 
of CRP clearance may result in CRP serum level increase. Similarly, slow CRP uptake in target cells might also add to this phenomenon. CRP levels have not been routinely used to diagnose thyroid disease, although many thyroid conditions involve inflammation [57].

On the other hand, troponin is a very useful marker within the heart; cTnI appears to be uniformly distributed throughout the atria and ventricles. This absolute specificity of cTnI for cardiac tissue makes it an ideal biomarker of myocardial injury. Our study showed that cardiac troponin I levels were drastically higher in hypothyroid rats compared to control rats in both periods of experiment, Cardiac troponin I begin to rise 4-8 hours after myocardial damage, peak at approximately 12 - 24 hours, and remain elevated for up to 10 days depending on the severity and duration of the hypothyrodism. It should be remembered that cardiac troponins reflect myocardial damage but do not indicate its mechanism. Thus, an elevated value in the absence of clinical evidence of ischemic heart disease should prompt a search for situations in which various degrees of myocardial injury may be present [58].

Our study suggests that level of inflammatory markers was relatively higher in hypothyroid rats than control group and they were positively correlated with TSH (thyroid dysfunction) level in hypothyroid group. Also there were highly significant correlations between LDH and CRP with all parameters. These results were confirmed in our study by histopathological assessment that showed inflammation and fibrosis.

\section{Conclusion:-}

From our data we conclude that:

1- There is interdependence between inflammation, hyperlipidemia and suppression of antioxidant capacity and these factors can exert profound effect on the risk of atherosclerosis and cardiovascular disease in this hypothyroidism model.

2- This Connection depends on the degree and the duration of thyroid hormone deficiency and the level of TSH.

3- LDH and CRP correlate more parallel with this hypothyroidism model in rats.

4-Over the past several decades, the use of cardiac biomarkers has greatly improved the diagnosis of heart diseases even for longer periods of affections. As more markers have emerged, sensitivity and specificity has increased and time to diagnosis and treatment has decreased. Currently, the best marker available in clinical practice is troponin however; even troponin results should be interpreted within a clinical context and not used in isolation. Furthermore, there is still room for improvement and current research seems to suggest there are more markers still to come which will improve cardiac affections diagnostics, prognostics and prediction.

\section{Acknowledgments:-}

We are grateful to Dr. Sherif Moawed for his comments and suggestions in statistical analysis.

\section{References:-}

1. Tendera M, Wojakowski W (2010). How to measure the effects of the intracoronary stem cell therapy? Eur $\mathbf{J}$ Echocardiogr 11: 438-439.

2. Danzi, S., Ojamaa, K., Klein, I., (2003). Triiodothyronine-mediated myosin heavy chain gene transcription in the heart. Am. J. Physiol. Heart Circ. Physiol. 284, 2255-2262.

3. Scruggs, S.B., Walker, L.A., Lyu, T., Geenen, D.L., Solaro, R.J., Buttrick, P.M., Goldspink, P.H., (2006). Partial replacement of cardiac troponin I with a non-phosphorylatable mutant at serines 43/45 attenuates the contractile dysfunction associated with PKCepsilon phosphorylation. J. Mol. Cell. Cardiol. 40, 465-473.

4. Biondi B (2007). Cardiovascular effects of mild hypothyroidism. Thyroid 17: 625- 630.

5. Pingitore, A., Iervasi, G., Barison, A., Prontera, C., Pratali, L., Emdin, M., Giannessi, D., Neglia, D., (2006). Early activation of an altered thyroid hormone profile in asymptomatic or mildly symptomatic idiopathic left ventricular dysfunction. J. Card. Fail. 12, 520-526.

6. SILVA, C.M.; SERAKIDES, R.; OLIVEIRA, T.S. et al. (2004). Histomorfometria e histoquímica dos ovários, tubas e útero de ratas hipotireoideas em metaestro-diestro. Arq. Bras. Med. Vet. Zootec., v.56, p.628-639, 2004.

7. Pol CJ, Muller A, Zuidwijk MJ, van Deel ED, Kaptein E, et al. (2011). Left ventricular remodeling after myocardial infarction is associated with a cardiomyocyte-specific hypothyroid condition. Endocrinology 152: 669679.

8. Chattopadhyay, S.; Zaidi, G.; Das, K.; Chainy, G.N.B. (2003). Effects of hypothyroidism induced by 6-npropylthiouracil and its reversal by $\mathrm{T} 3$ on rat heart superoxide dismutase, catalase and lipid peroxidation. Indian J. Exp. Biol., 41, 846-849. 
9. Elahi, M.M.; Kong, Y.X.; Matata, B.M. (2009). Oxidative stress as a mediator of cardiovascular disease. Oxid. Med. Cell Longev. , 2, 259-269.

10. Hennig, B.; Toborek, M.; McClain, C.J. (2001). High-energy diets, fatty acids and endothelial cell function: implications for atherosclerosis. J. Am. Coll. Nutr. 2001, 20, 97-105.

11. Mertens, A.; Verhamme, P.; Bielicki, J.K.; Phillips, C.; Quarck, R.; Verreth, W.; Stengel, D.; Ninio, E.; Navab, M.; Mackness, B.; et al. (2003). Increased low-density lipoprotein oxidation and impaired high-density lipoprotein antioxidant defense are associated with increate macrophage homing and atherosclerosis in dyslipidemic obese mice: LCAT gene transfer decreases atherosclerosis. Circulation, 107, 1640-1646.

12. Chen W, Frangogiannis NG (2013). Fibroblasts in post-infarction inflammation and cardiac repair. Biochim Biophys Acta 1833: 945-953.

13. Drobnik J, Ciosek J, Slotwinska D, Stempniak B, Zukowska D, et al. (2009). Experimental hypothyroidism increases content of collagen and glycosaminoglycans in the heart. J Physiol Pharmacol 60: 57-62.

14. Zhang Y, Huang XR, Wei LH, Chung AC, Yu CM, et al. (2014). miR-29b as a therapeutic agent for angiotensin II-induced cardiac fibrosis by targeting TGFbeta/ Smad3 signaling. Mol Ther 22: 974-985.

15. Rainer PP, Hao S, Vanhoutte D, Lee DI, Koitabashi N, et al. (2014). Cardiomyocyte-specific transforming growth factor beta suppression blocks neutrophil infiltration, augments multiple cytoprotective cascades, and reduces early mortality after myocardial infarction. Circ Res 114: 1246-1257.

16. Diekman MJ, Anghelescu N, Endert E, Bakker O, Wiersinga WM. (2000). Changes in plasma low-density lipoprotein (LDL) - and high-density lipoprotein cholesterol in hypo- and hyperthyroid patients are related to changes in free thyroxine, not to polymorphisms in LDL receptor or cholesterol ester transfer protein genes. J Clin Endocrinol Metab ;85:1857-1862.

17. Bartoz, G. (2003.) Total antioxidant capacity. Adv. Clin. Chem., 37, 219-292.

18. Chevion, S.; Chevion, M. (2000). Antioxidant status and human health. Use of cyclic voltammetry for the evaluation of the antioxidant capacity of plasma and of edible plants. Ann. N. Y. Acad. Sci. 2000, 899, 308-325.

19. Lowe GD. (2005). Circulating inflammatory markers and risks of cardiovascular and non-cardiovascular disease. J Thromb Haemost. 2005;3(8):1618-27.

20. Koenig W, Khuseyinova N, Baumert J et al (2008). Prospective study of high-sensitivity C-reactive protein as a determinant of mortality: results from the MONICA/KORA Augsburg Cohort Study, 1984-1998. Clin Chem 54:335342

21. Hekimsoy Z, Oktem IK. (2005). Serum creatine kinase levels in overt and subclinical hypothyroidism. Endocr Res 2005;31(3):171-5.

22. Sakaki T, Fujioka Y, Akagami T, Masai M, Shimizu H, Sakoda T, et al. (2004). Cardiac wall motion abnormalities observed in a patient with transient hyperthyroidism. Jpn Heart J;45(6):1071-7.

23. Pearson TA, Mensah GA, et al. (2003). Markers of Inflammation and Cardiovascular Disease. Circulation. ;107:499-511.

24. Pepys MB, Hirschfield GM (2003). C-reactive protein: a critical update. J Clin Invest 111:1805-1812

25. Yu YT, Ho CT, Hsu HS, Li CI, Davidson LE, Liu CS. (2013). Subclinical hypothyroidism is associated with elevated high sensitive C-reactive protein adult Taiwanese. Endocrine. ;44(3):716-22.

26. Fazio S, Palmieri EA, Lombardi G, Biondi B (2004). Effects of thyroid hormone on the cardiovascular system. Recent Prog Horm Res 59: 31-50.

27. Rhee SS, Pearce EN (2011). Update: Systemic Diseases and the Cardiovascular System (II). The endocrine system and the heart: a review. Rev Esp Cardiol 64: 220-231.

28. Zhang Y, Post WS, Cheng A, Blasco-Colmenares E, Tomaselli GF, et al. (2013). Thyroid hormones and electrocardiographic parameters: findings from the third national health and nutrition examination survey. PLoS One 8: e59489.

29. Biondi B, Wartofsky L (2014) Treatment with thyroid hormone. Endocr Rev 35: 433-512.

30. Biondi B (2012). Mechanisms in endocrinology: Heart failure and thyroid dysfunction. Eur J Endocrinol 167: 609618.

31. Davis PJ, Leonard JL, Davis FB (2008). Mechanisms of nongenomic actions of thyroid hormone. Front Neuroendocrinol 29: 211-218.

32. Ujwal Upadya B, Suma MN, Srinath KM, Prashant A, Doddamani P, Sv S. (2015). Effect of insulin resistance in assessing the clinical outcome of clinical and subclinical hypothyroid patients. J Clin Diagn Res;9(2):OC01-04.

33. Tang YD, Kuzman JA, Said S, Anderson BE, Wang X, et al. (2005). Low thyroid function leads to cardiac atrophy with chamber dilatation, impaired myocardial blood flow, loss of arterioles, and severe systolic dysfunction. Circulation 112: 3122-3130.

34. Institute of Laboratory Animal Research I. Guide for the Care and Use of Laboratory Animals. Washington, National academy press. (1996). 
35. Weltman NY, Ojamaa K, Savinova OV, Chen YF, Schlenker EH, et al. (2013). Restoration of cardiac tissue thyroid hormone status in experimental hypothyroidism: a dose-response study in female rats. Endocrinology 154: 2542-2552.

36. Wang YY, Morimoto S, Du CK, Lu QW, Zhan DY, et al. (2010). Upregulation of type 2 iodothyronine deiodinase in dilated cardiomyopathy. Cardiovasc Res 87: 636-646.

37. Tschirgi ML, Rajapakse I, Chandra M (2006). Functional consequence of mutation in rat cardiac troponin $\mathrm{T}$ is affected differently by myosin heavy chain isoforms. J Physiol 574: 263-273.

38. Das, K., Chainy, G.B.N., (2001). Modulation of liver mitochondrial antioxidant defense system by thyroid hormone. Biochem. Biophys. Acta 1573, 1-13.

39. Badarinath, A., K. Rao, C. Chetty, S. Ramkanth, (2010) aspartame in wistar albino rats. Asian. Pac. J. Trop. T. Rajan and K. Gnanaprakash, 2010. A review on Dis., 4(1): 930-937. in-vitro antioxidant methods: Comparisions, 56. Bergesio, F., G. Monzani, R. Ciuti, P. Pinzani, correlations and considerations. Int. J. Pharm. Tech. N. Fiaschi, F. Priami, C. Cirami, C. Ciccarelli and Res., 2: 1276-1285.

40. Friedewald WT, Levy RI, Fredrickson DS. (1972). Estimation of the concentration of low-density lipoprotein cholesterol in plasma, without use of the preparative ultracentrifuge. Clin Chem ;18:499-502.

41. Bancroff, J., Stevenes, A., Turner, D., (1990). Theory and Practice of Histological Techniques, 3rd ed. Clurechill Livingston, Edinburgh, London.

42. Refetoff S, Franklyn J, Shephard M (2014). 6E - Evaluation of Thyroid Function in Health and Disease. Leslie DeGroot, editor. Available: http://www.thyroidmanager.org/.

43. Duntas, L.H., Orgiazzi, J., Brabant, G., (2011). The interface between thyroid and diabetes mellitus. Clin. Endocrinol. 75, 1-9.

44. Kumar, K., Kole, A.K., Karmakar, P.S., Ghosh, A., (2012). The spectrum of thyroid disorders in systemic lupus erythematosus. Rheumatol. Int. 32, 73-78.

45. Klein I, Danzi S (2007). Thyroid disease and the heart. Circulation 116: 1725- 1735.

46. Samuels MH, Kolobova I, Smeraglio A, Peters D, Janowsky JS, et al. (2014). The effects of levothyroxine replacement or suppressive therapy on health status, mood, and cognition. J Clin Endocrinol Metab 99: 843-851.

47. Razvi S, Weaver JU, Butler TJ, Pearce SH (2012). Levothyroxine treatment of subclinical hypothyroidism, fatal and nonfatal cardiovascular events, and mortality. Arch Intern Med 172: 811-817.

48. x.Zhu and S.Y.Cheng, (2010). "New insight into regulation of lipid metabolism by thyroid hormone", Current Opinion in Endocrinology, Diabetes and Obesity, vol.17, no. 5, pp. 408-413,2010.

49. Irwin Klein, Sara Danzi. (2007). Thyroid disease and the heart cardiovascular involvement in general medical conditions. Circulation;116:1725-35.

50. Galesanu, C.,Lisnic, N., Teslaru, R., Apostu, L., Zbrance, E.(2004). Lipid Profile in a group of hypothyroid patients Vs treated hypothyroid patients. Rev. Med. Chir. Soc. Med. Nat. lasi. 108(3), 554-560.

51. Peppa M, Betsi G, Dimitriadis G. (2011). Lipid abnormalities and cardiometabolic risk in patients with overt and subclinical thyroid disease. J Lipids. 2011;2011:575840.

52. Yogeeta, S.K., Gnanapragasam, A., Kumar, S.S., Subhashini, R., Sathivel, A., Devaki, T., (2006). Synergistic interactions of ferulic acid with ascorbic acid: its cardioprotective role during isoproterenol induced myocardial infarction in rats. Mol. Cell. Biochem. 283, 139-146.

53. Rajadurai, M., Stanely, M.P.P., (2007). Preventive effect of naringin on cardiac markers, electrocardiographic patterns and lysosomal hydrolases in normal and isoproterenol induced myocardial infarction in Wistar rats. Toxicology 230, 178-188.

54. Järvisalo MJ, Juonala M, Raitakari OT (2006) Assessment of inflammatory markers and endothelial function. Curr Opin Clin Nutr Metab Care 9:547-552

55. Karoli R, Fatima J, Shukla V, Chandra A, Khanduri S, Rawat A. (2014) hospital based study of carotid intima media thickness and high sensitivity C-reactive protein in young hypothyroid patients. JIACM. 2014;15(2):116-19.

56. Wonn-Young L, Jung-Yul S, Eun-Jung R, Jeong-Sik P, Ki-Chul S, Sun-Woo K. (2004). Plasma CRP, Apolipoprotein A-1, Apolipoprotein B and Lp (a) levels according to thyroid function status. Arch Med Res;35:540545.

57. Dizdarevic-Bostandic A, Burekovic A, Velija-Asimi Z, Godinjak A (2013). Inflammatory markers in patients with hypothyroidism and diabetes mellitus type 1. Med Arh 67: 160-161.

58. Bodor GS. (2004) Cardiac troponins: A decade of change in cardiac marker testing. LabMedica International Vol. 21 № 2 3-4, 13-14. 